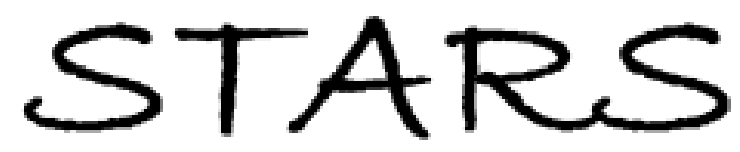

University of Central Florida

STARS

$1-1-1995$

\title{
Fullerene Formation During Production Of Chemical Vapor Deposited Diamond
}

\author{
Lee Chow \\ University of Central Florida \\ Hao Wang \\ University of Central Florida \\ Stephen Kleckley \\ University of Central Florida \\ Terry K. Daly \\ Peter R. Buseck
}

Find similar works at: https://stars.library.ucf.edu/facultybib1990

University of Central Florida Libraries http://library.ucf.edu

This Article is brought to you for free and open access by the Faculty Bibliography at STARS. It has been accepted for inclusion in Faculty Bibliography 1990s by an authorized administrator of STARS. For more information, please contactSTARS@ucf.edu.

\section{Recommended Citation}

Chow, Lee; Wang, Hao; Kleckley, Stephen; Daly, Terry K.; and Buseck, Peter R., "Fullerene Formation During Production Of Chemical Vapor Deposited Diamond" (1995). Faculty Bibliography 1990s. 2991.

https://stars.library.ucf.edu/facultybib1990/2991

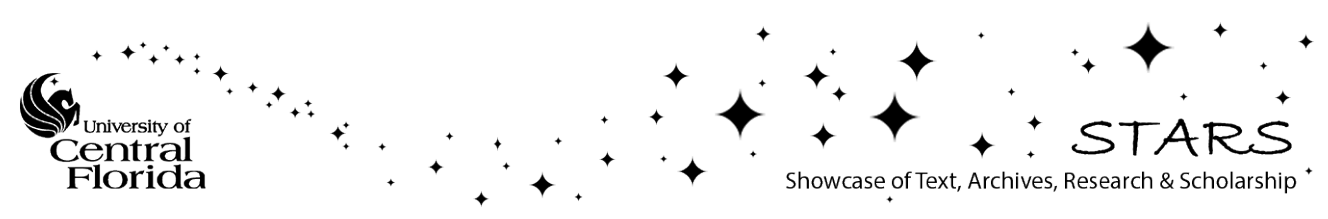




\section{Fullerene formation during production of chemical vapor deposited diamond}

Cite as: Appl. Phys. Lett. 66, 430 (1995); https://doi.org/10.1063/1.114046

Submitted: 11 August 1994 . Accepted: 11 November 1994 . Published Online: 04 June 1998

Lee Chow, Hao Wang, Stephen Kleckley, Terry K. Daly, and Peter R. Buseck

\section{ARTICLES YOU MAY BE INTERESTED IN}

Large-scale and low-cost synthesis of single-walled carbon nanotubes by the catalytic pyrolysis of hydrocarbons

Applied Physics Letters 72, 3282 (1998); https://doi.org/10.1063/1.121624

Physical vapor deposition of highly oriented fullerene $\mathrm{C}_{60}$ films on amorphous substrates Journal of Applied Physics 77, 3572 (1995); https://doi.org/10.1063/1.358592

The UV absorption spectrum of $\mathrm{C}_{60}$ (buckminsterfullerene): A narrow band at $3860 \AA$ The Journal of Chemical Physics 87, 4236 (1987); https://doi.org/10.1063/1.452879

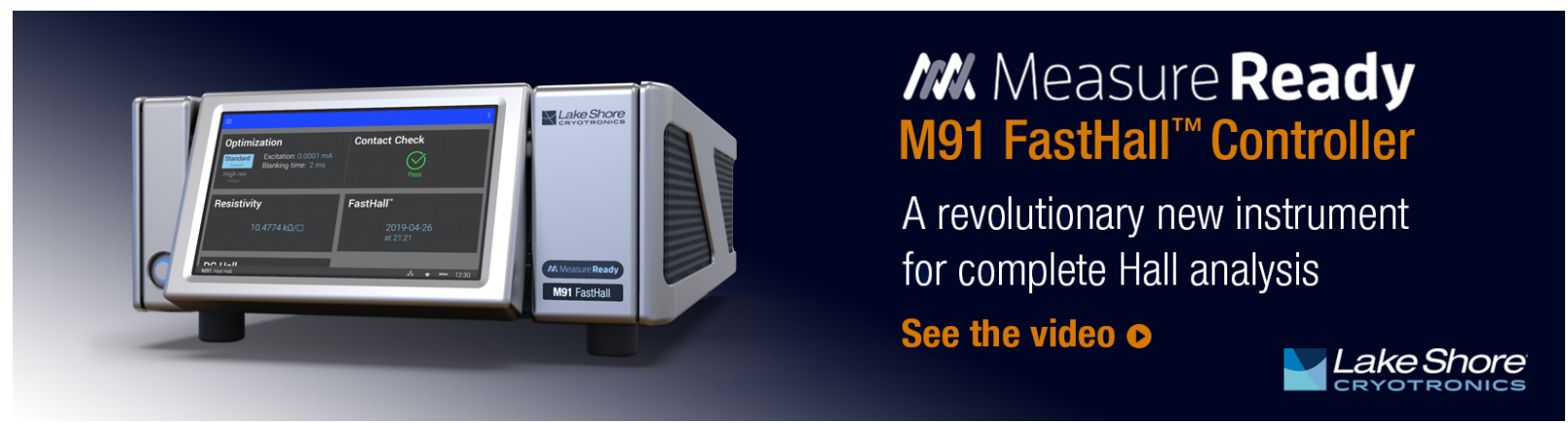




\title{
Fullerene formation during production of chemical vapor deposited diamond
}

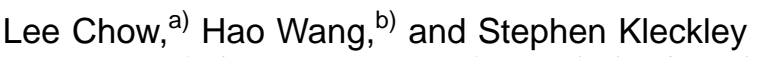 \\ Department of Physics, University of Central Florida, Orlando, Florida 32816-2385 \\ Terry K. Daly and Peter R. Buseck \\ Department of Geology \& Chemistry/Biochemistry, Arizona State University, Tempe, Arizona 85287-1404
}

(Received 11 August 1994; accepted for publication 11 November 1994)

\begin{abstract}
We report a novel method for fullerene formation during diamond synthesis via a hot filament, chemical vapor deposition (CVD) procedure. The fullerenes occur in the soot that forms as a by-product on the edges and rear surface of the substrate holder, where the temperature does not favor diamond deposition. Mass spectrometry of the soot shows a peak having a mass to charge ratio corresponding to $\mathrm{C}_{60}$. From typical concentrations of gaseous species in the diamond-growing CVD chamber, we conclude that hydrocarbon species such as $\mathrm{CH}_{3}$ or $\mathrm{C}_{2} \mathrm{H}_{2}$ may be the precursors for the fullerene in the CVD chamber. The atomic hydrogen in the gaseous species is believed to play an important role in removing the hydrogen from hydrocarbon to form the all-carbon fullerene. Our observations also suggest that fullerenes produced in the CVD diamond growth chamber play a role in diamond nucleation on foreign substrates. (C) 1995 American Institute of Physics.
\end{abstract}

In 1985 , Kroto et al. ${ }^{1}$ produced microscopic quantities of fullerenes (most notably $\mathrm{C}_{60}$ and $\mathrm{C}_{70}$ ) in a supersonic molecular beam. Subsequently Kratschmer et $a .^{2}$ developed a method of producing macroscopic quantities of fullerenes using a carbon-arc apparatus. While these developments led to intense research into the physical and chemical properties of this unique class of carbon molecules, the precise nature of their formation ${ }^{3}$ remains controversial. Here we report a new method of forming fullerenes using hot-filament chemical vapor deposition (CVD), which is a standard method for diamond thin-film growth.

The experiments were performed in a conventional hotfilament CVD chamber ${ }^{4}$ using a straight $0.75-\mathrm{mm}$ diameter tungsten filament approximately $8 \mathrm{~cm}$ in length. The current was maintained between 50 and $55 \AA$, and the filament temperature was estimated to be $\approx 2200{ }^{\circ} \mathrm{C}$. The feed gases were $99.8 \%$ pure $\mathrm{CH}_{4}$ mixed with $99.999 \%$ pure $\mathrm{H}_{2}$. The chamber pressure was kept between 30 and 35 Torr. Flow rates were controlled at $0.4 \mathrm{sccm}$ for $\mathrm{CH}_{4}$ and at $99.6 \mathrm{sccm}$ for $\mathrm{H}_{2}$. A stainless-steel substrate holder was used, and a scratched $\mathrm{Si}$ wafer served as the substrate. Substrate temperatures, as monitored by both thermocouple and pyrometer, were kept between 850 and $900{ }^{\circ} \mathrm{C}$ to optimize diamond deposition. Runs lasted between 5 and 24 h. After each diamond deposition, the soot was collected from the substrate holder. Typically 10-75 mg of soot was collected after each run.

Samples of the collected soot (about $100 \mathrm{mg}$ ) were analyzed by mass spectrometry using the procedure described by Daly et al. ${ }^{5}$ The signal at a mass-to-charge ratio of 720 in Fig. 1 indicates the presence of $\mathrm{C}_{60}$. Another set of samples was collected under similar conditions to those described above and laser-desorption time-of-flight mass spectrometry was employed to study the soot. To avoid ambiguous results,

\footnotetext{
a) To whom correspondence should be addressed. Electronic mail: 1c@phys.physics.ucf.edu.

${ }^{b)}$ Current Address: Shanghai Institute of Optics and Fine Mechanics, Academia Sinica, P.O. Box 800-216, 201800 Shanghai, P. R. China.
}

we used low laser power density ${ }^{6}\left(10^{5}-10^{7} \mathrm{~W} / \mathrm{cm}^{2}\right)$ and we also repeated the measurement with a sample (Antelope coal) that is known to contain only graphitic material and no fullerenes. The results are shown in Figs. 2(a) and 2(b). In addition, we carried out $\mathrm{UV}$-vis absorption spectroscopy of soot dissolved in a $\mathrm{CCl}_{4}$ solution. After the solution was passed through filter paper, the absorption spectrum was taken with a Perkin-Elmer model No. 552 spectrophotometer. The result illustrated in Fig. 3 shows strong absorption bands at 259 and $328 \mathrm{~nm}$, in agreement with the absorption spectrum of $\mathrm{C}_{60}$ reported by Ajie et al. ${ }^{7}$ in the wavelength range of $255-500 \mathrm{~nm}$. Because of the $\mathrm{CCl}_{4}$ solvent, no signal can be detected below the $255 \mathrm{~nm}$ cutoff wavelength.

In an attempt to increase the yield of fullerenecontaining soot, we modified the growth conditions to $2 \%-5 \% \mathrm{CH}_{4}$ with $95 \%-98 \% \mathrm{H}_{2}$, and kept the substrate holder at a lower temperature $\left(400-750{ }^{\circ} \mathrm{C}\right)$ by moving the

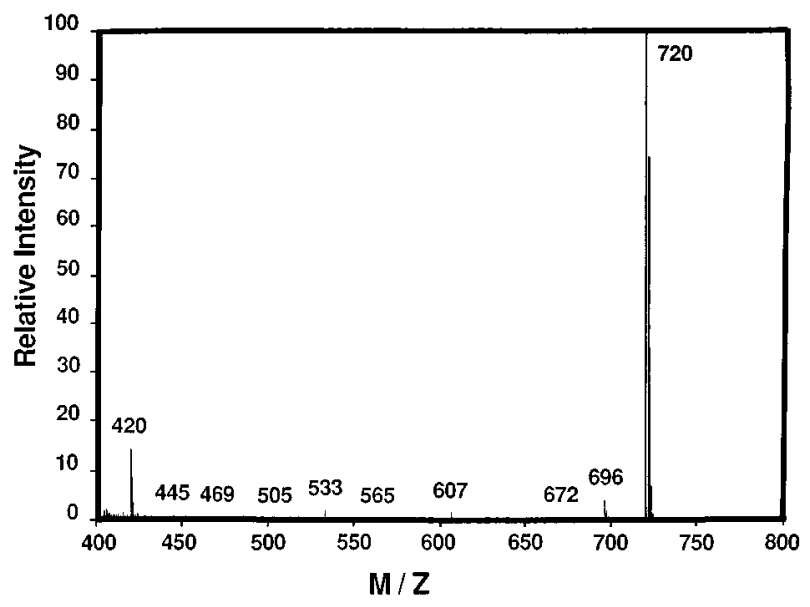

FIG. 1. The mass spectrum of soot collected in the hot-filament CVD diamond-growth chamber. 

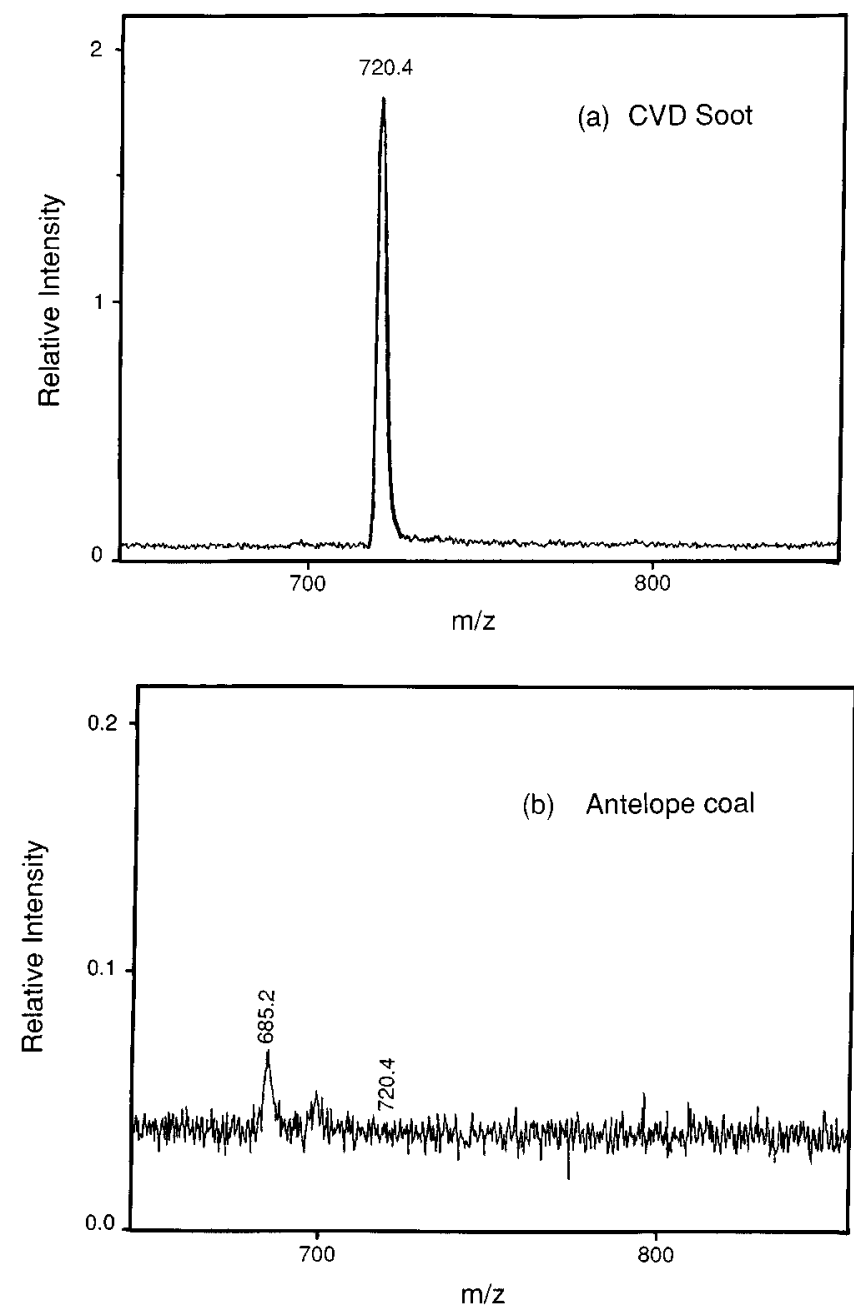

FIG. 2. Laser-desorption time-of-flight mass spectrum of (a) CVD soot, and (b) antelope coal.

substrate holder away from the filament. Pressure and filament current conditions were unchanged, and the total flow rate remained at $100 \mathrm{sccm}$. In this way we were able to increase the soot production rate sixfold to about 10-20 $\mathrm{mg} / \mathrm{h}$. However, under these conditions diamond was not produced, and mass spectrometry of the soot showed no sign of fullerenes, although some hydrocarbon clusters were present. These results could imply that the atomic hydrogen plays an important role in the formation of fullerene under this condition. It has been shown ${ }^{8}$ that the atomic hydrogen concentration decreases as the initial methane concentration increases.

The environment in the hot-filament CVD chamber differs considerably from those during either laser vaporization or carbon-arc synthesis. Under typical diamond-forming conditions of 30-80 Torr of $0.5 \% \mathrm{CH}_{4}$ and $99.5 \% \mathrm{H}_{2}$ and a filament temperature of $2000-2200{ }^{\circ} \mathrm{C}$, the atomic carbon concentration in the CVD chamber is several orders of magnitude lower than most of the hydrocarbon species that are present. Both calculations ${ }^{9,10}$ and experimental measurements ${ }^{11,12}$ have shown that under such conditions $\mathrm{H}, \mathrm{C}_{2} \mathrm{H}_{2}$, $\mathrm{CH}_{3}$, and $\mathrm{CH}_{4}$, in addition to $\mathrm{H}_{2}$, are the predominating species. It is generally accepted that hydrocarbons like acety-

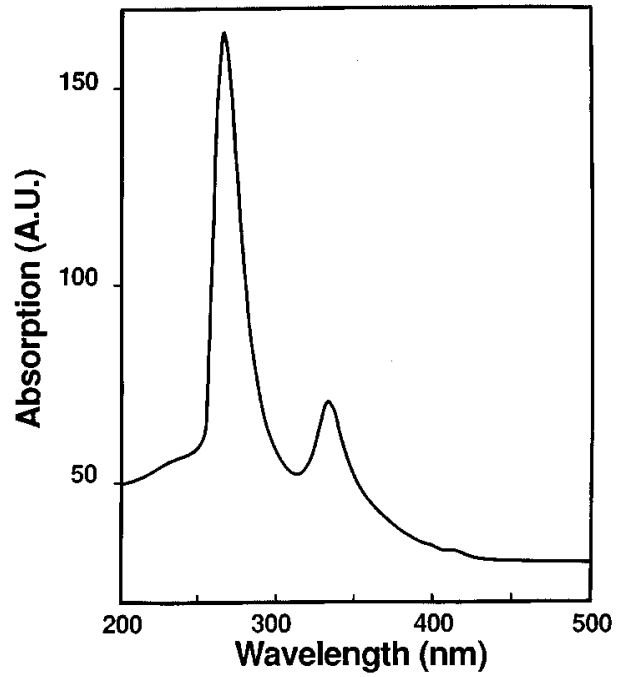

FIG. 3. Ultraviolet-visible spectrum of soot dissolved in $\mathrm{CCl}_{4}$ solution.

lene or methyl radicals rather than carbon atoms are the precursors of diamond growth, and atomic hydrogen plays a major role in etching graphitic material and in promoting the diamond growth.

Here we propose that the $\mathrm{C}_{60}$ found in the diamondforming CVD chamber may also be from hydrocarbon precursors. The process could be similar to the fullerene production in hydrocarbon flames, ${ }^{13-15}$ namely, the growth of the hydrocarbon precursors of the fullerene is mainly through the addition of acetylene and hydrogen abstraction. Both atomic hydrogen and acetylene are present in our CVD chamber. Our current operating parameters are optimized for diamond growth, so the formation of $\mathrm{C}_{60}$ is clearly a minor effect. A systematic investigation of the conditions under which fullerenes can be formed is now in progress.

One implication of our finding relates to the nucleation of diamond. During CVD diamond growth, Si substrates are normally scratched with diamond powder before deposition in order to increase the diamond nucleation density. However diamond can also be nucleated on an unscratched Si sub-

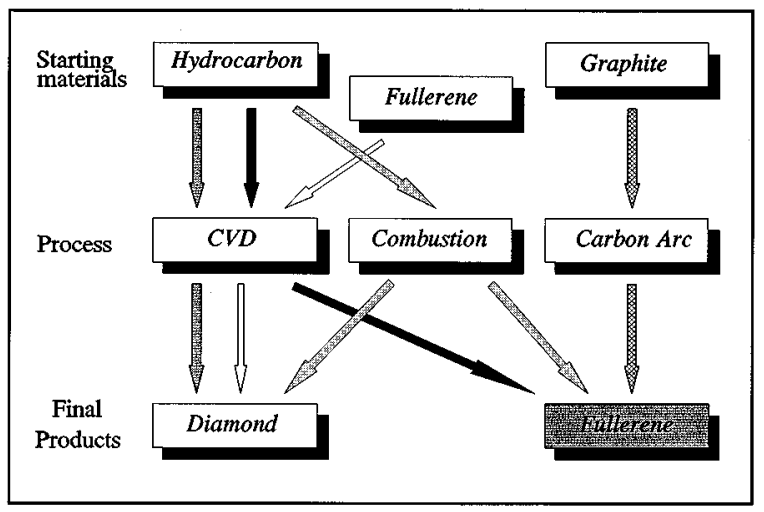

FIG. 4. Several processes using different starting materials to produce diamond and fullerene are shown here. The process reported here is shown by the solid arrows. 
strate, although at a much lower rate. It has been proposed that either $\mathrm{SiC}^{16}$ or some form of graphite ${ }^{17}$ acts as the nucleation site when the $\mathrm{Si}$ substrate is not prescratched. It was recently found that ion-activated fullerene films on $\mathrm{Si}$ substrates increase the diamond nucleation rate by 10 orders of magnitude. ${ }^{18}$ This, coupled with our observation of fullerenes in the CVD diamond-forming chamber, could imply that fullerenes or precursors of fullerenes which formed in the CVD chamber may also play a role in the nucleation of diamond on unscratched foreign substrates. Recently, Gruen et al. ${ }^{19,20}$ have shown that fullerenes can be used as precursors for CVD diamond thin-film deposition. They proposed that $\mathrm{C}_{2}$, observed in the $\mathrm{C}_{60}$ fragmentation process, is the principal growth species under the condition of their experiment. It should be noted that our observation of fullerene formation in the CVD diamond growing chamber reported here is a totally different process from the diamond growth using fullerene as a precursor as reported by Gruen et al. ${ }^{19,20}$ This difference is perhaps best seen in Fig. 4, where different techniques capable of producing diamond and fullerene, are shown. In Fig. 4, our process is represented by the solid arrow, while Gruen et al.'s work is represented by the thin arrow. The figure clearly indicates a strong correlation between the formation processes of diamond and fullerene.

The authors at UCF acknowledge partial support from the Division of Sponsored Research and Training, University of Central Florida. The ASU portion of this study was supported by NSF Grant no. EAR-9219376 (to PRB). They thank Dr. J. P. Lehman, Dr. D. C. Brune, D. G. Hartzfeld, and J. E. Hughes of ASU for help with the mass spectrometry and Dr. M. Hampton of UCF for the UV-vis absorption measurments.
${ }^{1}$ H. W. Kroto, J. R. Heath, S. C. O’Brien, R. F. Curl, and R. E. Smalley, Nature 318, 162 (1985).

${ }^{2}$ W. Kratschmer, L. Lamb, K. Fostiropoulos, and D. R. Hoffman, Nature 347, 354 (1990).

${ }^{3}$ R. F. Curl, Nature 363, 14 (1993).

${ }^{4}$ W. A. Yarbrough, K. Tankala, and T. DebRoy, J. Mater. Res. 7, 379 (1992).

${ }^{5}$ T. K. Daly, P. R. Buseck, P. Williams, and C. F. Lewis, Science 259, 1599 (1993).

${ }^{6}$ P. R. Buseck, S. J. Tsipursky, and R. Hettich, Science 257, 215 (1992).

${ }^{7}$ H. Ajie, M. M. Alvarez, S. J. Anz, R. D. Beck, F. Diederich, K. Fostiropoulos, D. R. Huffman, W. Kratschmer, Y. Rubin, K. E. Schriver, D. Sensharma, and R. L. Whetten, J. Phys. Chem. 94, 8630 (1990).

${ }^{8}$ S. J. Harris and A. M. Weiner, J. Appl. Phys. 67, 6520 (1990).

${ }^{9}$ B. V. Spitsyn, J. Cryst. Growth, 99, 1162 (1990); B. V. Spitsyn, in Application of Diamond Films and Related Materials, edited by Y. Tzeng, M. Yoshikawa, M. Murakawa, and A. Feldman (Elsevier, Amsterdam, 1991), p. 475.

${ }^{10}$ M. Frenklach and H. Wang, Phys. Rev. 43, 1520 (1991).

${ }^{11}$ S. J. Harris, A. M. Weiner, and T. A. Perry, Appl. Phys. Lett. 53, 1605 (1988).

${ }^{12}$ F. G. Celii and J. E. Butler, J. Appl. Phys. 71, 2877 (1992).

${ }^{13}$ J. B. Howard, J. T. McKinnon, Y. Markovsky, A. L. Lafleur, and M. E. Johnson, Nature 352, 139 (1991).

${ }^{14}$ A. L. Lafleur, J. B. Howard, J. A. Marr, and T. Yadav, J. Phys. Chem. 97, 13539 (1993).

${ }^{15}$ C. J. Pope, J. A. Marr, and J. B. Howard, J. Phys. Chem. 97, 11001 (1993).

${ }^{16}$ A. Badzian, T. Badzian, R. Roy, R. Messier, and K. E. Spear, Mater. Res. Bull. 23, 531 (1988).

${ }^{17}$ W. R. L. Lambrecht, C. H. Lee, B. Segal, J. C. Angus, Z. Li, and M. Sunkara, Nature 364, 607 (1993).

${ }^{18}$ R. Meilunas, R. H. M. Chang, S. Z. Lu, and M. M. Kappes, Appl. Phys. Lett. 59, 3461 (1991).

${ }^{19}$ D. M. Gruen, S. Liu, A. R. Krauss, and X. Pan, J. Appl. Phys. 75, 1758 (1994).

${ }^{20}$ D. M. Gruen, S. Liu, A. R. Krauss, J. Luo, and X. Pan, Appl. Phys. Lett. 64, 1502 (1994). 